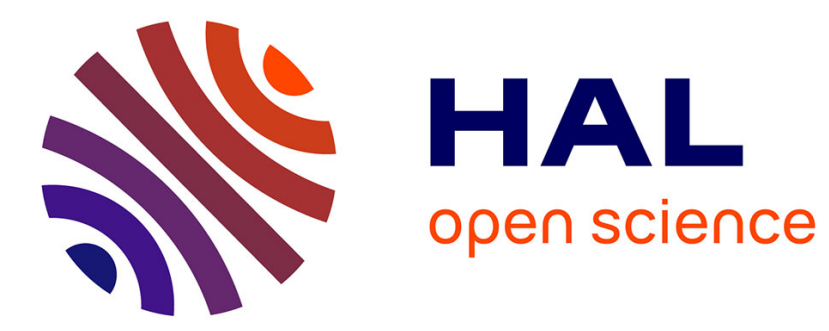

\title{
Biodiversity loss along a gradient of deforestation in Amazonian agricultural landscapes
}

Thibaud Decaens, Marlucia Martins, Alex Feijoo, Johan Oszwald, Sylvain Dolédec, Jérôme Mathieu, Xavier Arnauld de Sartre, Diego Bonilla, George Brown, Yeimmy Andrea Cuellar Criollo, et al.

\section{To cite this version:}

Thibaud Decaens, Marlucia Martins, Alex Feijoo, Johan Oszwald, Sylvain Dolédec, et al.. Biodiversity loss along a gradient of deforestation in Amazonian agricultural landscapes. Conservation Biology, 2018, 32 (6), pp.1380 - 1391. 10.1111/cobi.13206 . hal-01922346

\section{HAL Id: hal-01922346 https://hal.science/hal-01922346}

Submitted on 27 Nov 2018

HAL is a multi-disciplinary open access archive for the deposit and dissemination of scientific research documents, whether they are published or not. The documents may come from teaching and research institutions in France or abroad, or from public or private research centers.
L'archive ouverte pluridisciplinaire HAL, est destinée au dépôt et à la diffusion de documents scientifiques de niveau recherche, publiés ou non, émanant des établissements d'enseignement et de recherche français ou étrangers, des laboratoires publics ou privés. 


\section{Biodiversity loss along a gradient of deforestation in Amazonian agricultural landscapes}

Thibaud Decaëns*1, Marlúcia B. Martins², Alexander Feijoo ${ }^{3}$, Johan Oszwald ${ }^{4}$, Sylvain Dolédec ${ }^{5}$, Jérôme Mathieu ${ }^{6}$, Xavier Arnaud de Sartre ${ }^{7}$, Diego Bonilla ${ }^{8}$, George G. Brown', Yeimmy Andrea Cuellar Criollo ${ }^{10}$, Florence Dubs ${ }^{11}$, Ivaneide S. Furtado ${ }^{2}$, Valérie Gond ${ }^{12}$, Erika Gordillo ${ }^{10}$, Solen Le $\mathrm{Clec}^{\prime} \mathrm{h}^{4}$, Raphaël Marichal13, Danielle Mitja ${ }^{14}$, Izildinha Miranda de Souza ${ }^{15}$, Catarina Praxedes2, Rodolphe Rougerie ${ }^{16}$, Darío H. Ruiz ${ }^{3}$, Joel Tupac Otero ${ }^{17}$, Catalina Sanabria ${ }^{18}$, Alex Velasquez ${ }^{10}$, Luz Elena M. Zararte ${ }^{19}$, Patrick Lavelle ${ }^{20}$

${ }^{1}$ Centre d'Ecologie Fonctionnelle et Evolutive, UMR 5175, CNRS-Univ Montpellier-Univ PaulValéry-EPHE-SupAgro Montpellier-INRA-IRD, Montpellier, France, email thibaud.decaens@cefe.cnrs.fr

${ }^{2}$ Laboratório de Ecologia de Invertebrados, Coordenação de Zoologia, Museu Paraense Emilio Goeldi, Avenida Perimetral 1901, Terra Firma, CEP 66077 530, Belém, Pará, Brazil

${ }^{3}$ Universidad Tecnológica de Pereira, Facultad de Ciencias Ambientales, Vereda La Julita, AA 97, 660003 Pereira, Risaralda, Colombia

${ }^{4}$ COSTEL, UMR CNRS 5654, Université de Rennes 2, 5 place Henri Le Moal, 35000 Rennes, France

${ }^{5}$ LEHNA, UMR 5023, Université Lyon 1, 43 Bd du 11 novembre 1918, 69622 Villeurbanne Cedex, France

${ }^{6}$ Sorbonne Universités, UPMC Univ Paris 06, iEES Paris, , 4 place Jussieu, 75005, Paris, France

${ }^{7}$ SET, UMR CNRS 5603, Université de Pau et des Pays de l'Adour, Avenue du Doyen Poplawski, 64000 Pau, France

${ }^{8}$ Insectos de Colombia, Yopal, Casanare, Colombia

${ }^{9}$ Embrapa Florestas, Estrada da Ribeira, km. 111, Caixa-Postal 319, CEP 83411 000, Curitiba, Parana, Brazil

10 Universidad de la Amazonia, Sede Principal, Calle 17 - Diagonal 17 con Carrera 3F, Barrio Porvenir, Florencia, Caquetá, Colombia

${ }^{11}$ IRD, iEES Paris, Centre IRD Ile de France, 32 Av. Henri Varagnat, 93143 Bondy Cedex, France

12 UR B\&SEF, CIRAD, Campus international de Baillarguet, 34398 Montpellier Cedex 5, France

${ }^{13}$ CIRAD, UPR Systèmes de pérennes, F-34398 Montpellier, France

${ }^{14}$ IRD, UMR Espace-DEV, MTD 500 rue Jean François Breton, 34093 Montpellier, Cedex 5

15 Universidade Federal Rural da Amazônia (UFRA), Avenida Perimetral 2501, CEP 66077530 , Belém, Pará, Brazil

This article has been accepted for publication and undergone full peer review but has not been through the copyediting, typesetting, pagination and proofreading process, which may lead to differences between this version and the Version of Record. Please cite this article as doi:

10.1111/cobi.13206.

This article is protected by copyright. All rights reserved. 
16 Institut de Systématique, Evolution, Biodiversité (ISYEB), Muséum national d'Histoire naturelle, CNRS, Sorbonne Université, EPHE, 57 rue Cuvier, CP 50, 75005 Paris, France 17 Universidad Nacional de Colombia, Sede Palmira, Carrera 32 No 12 - 00 Chapinero, Vía Candelaria, Palmira, Valle del Cauca, Colombia

18 Universidad del Valle, Cali, Colombia

${ }^{19}$ Instituto Tecnológico del Putumayo, Barrio Luís Carlos Galán, Mocoa, Putumayo, Colombia

${ }^{20}$ Centro Internacional de Agricultura Tropical (CIAT) - IRD, Cali, Valle del Cauca, Colombia

Keywords: biodiversity conservation; biodiversity erosion; Brazil; Colombia; landscape intensification; land-use changes; threshold

Running head: Biodiversity thresholds

Article impact statement: Tropical landscapes should retain over $40 \%$ of forests and $50 \%$ of unaffected patches to efficiently conserve biodiversity.

\begin{abstract}
Assessing how much management of agricultural landscapes, in addition to protected areas, can offset biodiversity erosion in the tropics is a central issue for conservation that still requires cross-taxonomic and landscape-scale studies. We measured the effects of Amazonia deforestation and subsequent land-use intensification in 6 agricultural areas (landscape scale), where we sampled plants and 4 animal groups (birds, earthworms, fruit flies, and moths). We assessed land-use intensification with a synthetic index based on landscape metrics (total area and relative percentages of land uses, edge density, mean patch density and diversity, and fractal structures at 5 dates from 1990 to 2007). Species richness decreased consistently as agricultural intensification increased despite slight differences in the responses of sampled groups. Globally, in moderately deforested landscapes species richness was relatively stable, and there was a clear threshold in biodiversity loss midway along the intensification gradient, mainly linked to a drop in forest cover and quality. Our results suggest anthropogenic
\end{abstract}


landscapes with high-quality forest covering $>40 \%$ of the surface area may prevent biodiversity loss in Amazonia.

\section{Introduction}

Tropical rainforests support some of the greatest diversities of living organisms on Earth (Myers 1984). The Amazonian forest in particular has been popularized as the last frontier forest and one of the most diverse regions in the world (Wilson 2002; Cardoso Da Silva et al. 2005). It is, however, dramatically threatened by ongoing deforestation resulting from expanding timber production and agricultural frontiers and by the increased frequency of largescale forest fires (Peres et al. 2010; Newbold et al. 2015). Recent estimates report a loss of about $770,000 \mathrm{~km}^{2}$ of forest from 1970 to 2016, nearly $20 \%$ of the original forest cover (Butler 2017). This gradual destruction of forest ecosystems and the resulting fragmentation and degradation of forest remnants are strongly affecting Amazonian biodiversity and the environmental sustainability of the whole region (Haddad et al. 2015; Barlow et al. 2016).

The protection of pristine forests in integral protected areas is vital to prevent loss of biodiversity. However, their current coverage remains limited and their integrity is frequently threatened in areas undergoing widespread deforestation (Rodrigues et al. 2004). They are also not representative of most of the tropical world, where the vast majority of tropical rainforests are not comprised within reserves and parks (Chazdon et al. 2009) and $>70 \%$ of remaining patches are within $1 \mathrm{~km}$ of the forest edge (Haddad et al. 2015). It is therefore important to focus not only on these protected areas, but also on the conservation value of agricultural landscapes, which are now replacing the pristine forest matrix at an increasing pace (Barlow et al. 2007a; Gardner et al. 2009; Chazdon et al. 2009). 
Significant theoretical and empirical advances have been made during the past decade in understanding of the relative importance of different landscape properties in explaining biodiversity loss in tropical rainforest biomes. For instance, recent studies emphasize the importance of habitat amount (Melo et al. 2017), landscape and within-forest disturbances (Barlow et al. 2016), and landscape configuration (Villard \& Metzger 2014) to explain the decline of biodiversity following deforestation. However, most of these studies considered only a single or a limited number of data-rich taxonomic groups, with a strong bias toward vertebrates or plants (Fazey et al. 2005; Gardner et al. 2009). Understanding of the relative sensitivity of different taxonomic groups to disturbance at the landscape level remains insufficient (Dunn 2004); some important components of terrestrial biodiversity, such as invertebrates, are weakly documented (Collen et al. 2009; Decaëns 2010).

Although ecological theory predicts a global decrease of biodiversity as ecosystem fragmentation increases (Andren 1994; Wilson 2002), the pattern of this decrease is still debated (Estavillo et al. 2013). Indeed, taxon- and guild-specific responses to the degradation or transformation of tropical forest have been reported repeatedly (Schulze et al. 2004; Barlow et al. 2007a; Newbold et al. 2014). Such idiosyncratic patterns may seriously hinder the ability to assess the global impact of deforestation when considering a limited number of indicator taxa. Comparative studies conducted at the landscape scale and across a wide range of taxa are thus critically needed to accurately assess the patterns of biodiversity loss along deforestation and agricultural intensification gradients and to identify the environmental drivers and potential thresholds and tipping points in the response of biodiversity to these perturbations (Newbold et al. 2014).

We measured the effects of Amazonia deforestation and the subsequent land-use intensification on seven different taxa including plants, vertebrates and invertebrates from above and below ground habitats at the landscape scale. Our main hypothesis was there exists a 
threshold in the response of biodiversity to gradual deforestation and landscape intensification beyond which species are extirpated at a higher rate. We thus expected biodiversity to decrease nonlinearly along a gradient of deforestation and agricultural intensity. This assumption was tested using a synthetic index of land-use intensity and specific landscape metrics related to habitat loss, habitat degradation, and land-use temporal dynamics.

\section{Methods}

\section{Study sites}

The study was carried out in Brazil (state of Pará) and Colombia (department of Caquetá) (Figure 1). We studied 3 areas per country that represented 6 different stages along a gradient of deforestation and agricultural intensification, from recently affected areas, where deforestation was in the early stage (Brazil), to regions with old agricultural histories and extensive pastures (Colombia) (Figure 1 \& Supporting Information). We did not examine pristine forests (i.e., the starting point of the deforestation process) because the extensive agricultural landscapes behind the Amazonian deforestation front no longer contain large areas of intact forests. In a socioeconomic survey X. Arnaud de Sartre categorized agricultural systems at 51 farms in each area (306 systems total) (see Supporting Information). We then selected from this initial pool a set of 54 farms ( 9 noncontiguous farms per area) that best represented the local production systems (Lavelle et al. 2016a). We further used this set of 54 farms as replicated elementary units to describe the landscape mosaic of the entire landscape and to measure species richness for the different target groups. At each farm, 5 equidistant sampling points ( $200 \mathrm{~m}$ from each other) were geolocated along a 1-km transect that ran along the longest diagonal line of the farm plot (Fig. 1). This design guaranteed a distribution of sampling effort among land uses that was proportional to relative representation of the uses within each farm. 


\section{Sampling}

We used standardized methods to sample plants and 4 groups of animals (earthworms, fruit flies, moths, and birds) on each farm. Groups were chosen for their link to soil ecosystem services (earthworms, plants [Diaz et al. 2007; Lavelle et al. 2016b]), sensitivity to local perturbations (fruit flies [Gottschalk et al. 2007]), or specific response to landscape composition and migrating abilities (moths and birds [Barlow et al. 2007b; Hawes et al. 2009]). Sampling was carried out from April to July 2008 with the aim of providing accurate and comparable estimates of species richness among the 6 study areas.

At each sampling point, a quadrat sampling area of $50 \times 50 \mathrm{~m}$ was defined within a homogeneous landscape element. For each taxonomic group, we determined the species composition and counted the number of individuals.

At each sampling point, plant species were counted in 3 vegetation strata in an area of a particular size: trees $>10 \mathrm{~cm}$ dbh in a $10 \times 50 \mathrm{~m}$ area; shrubs and young trees $<10 \mathrm{~cm}$ diameter and $>2 \mathrm{~m}$ tall in a $5 \times 50 \mathrm{~m}$ area; herbaceous species (spermatophytes and pteridophytes) and seedlings of both trees and shrubs in $10 \times 10 \mathrm{~m}^{2} 5 \mathrm{~m}$ from each other. For each species, samples were collected, dried in a field oven, and taken to the lab for identification.

Saturniidae and Sphingidae (moths) were collected with light trapping during a single collecting night at each transect for a total of 9 collecting night per study area. Traps were located as close as possible to the largest forest remnant on the farm. Moths were sampled throughout the night on moonless nights (i.e., from 1800 to 0600 [Lamarre et al. 2015]) with a white sheet ( $2 \mathrm{~m}$ height $\times 3 \mathrm{~m}$ width) illuminated by a $175 \mathrm{~W}$-mercury vapor bulb powered by a small portable generator. Specimens were killed by injection of ammonia, stored and dried in labeled paper envelopes, and brought to the laboratory for identification. 
Drosophilidae (fruit flies) were collected with cylindrical traps $(10 \mathrm{~cm}$ diameter $\times 25 \mathrm{~cm}$ height) closed at one extremity with a funnel at the other. Traps were baited with approximately $100 \mathrm{~g}$ of fermented banana (Martins et al. 2008). Three traps were placed at each sampling point and deployed for 48 hours. Specimens were fixed in $70 \%$ alcohol and taken to the laboratory for identification. When necessary, specimens were kept alive to allow laboratory rearing and more precise identifications.

Earthworms were collected by hand sorting 3blocks of soil at each sampling point: 1 central block of $25 \times 25 \times 30 \mathrm{~cm}$ and 2 blocks of $25 \times 25 \times 10 \mathrm{~cm}$ (1 block $5 \mathrm{~m}$ north of the central block and the other $5 \mathrm{~m}$ south of the central block). Individual specimens were fixed in 4\% formaldehyde and taken to the laboratory for identification. Because most of the collected species were new to science, morphospecies were defined on the basis of external and internal morphological characters, and the number of morphospecies was used as a surrogate for species richness.

Point counts for birds were conducted at each sampling point by two persons in a single 20-minute session in the morning (from approximately 0600 to 1100) to encompass the period of maximal bird activity. The total sampling effort was of 45 bird counts per study area.

Relying on a single sampling period and a single season could have led to undersampling of rare species or taxa with strong seasonal occupancy patterns. However, we considered our sampling strategy relevant to efficiently sampling, for each focal group, at least the dominant species that are active during the rainy season. This allowed us to conduct a broad comparison of diversity levels among the different study areas.

\section{Species richness}

Regional species richness was described by calculating the cumulative number of species observed in each area and the abundance-based coverage estimator (ACE), which provides an 
estimate of the theoretical size of the species pool (Chao \& Lee 1992). For rarefaction and extrapolation curves, we plotted the number of species according to sampling intensity (i.e., number of specimens collected or observed) and extrapolated this number in a hypothetical situation where the sampling size was doubled. This was done using the iNEXT package for R (R Development Core Team 2011; Chao \& Jost 2012).

At the farm scale, local species richness was rarefied for a subsample size that corresponded to the median density of each group of organism. For each farm, species richness transformed in this way represented the average number of species observed in a standardized sample of $n$ individuals, where $n$ is the median density of the corresponding target group and $n$ equaled 1586, 219, 35, 107, 30, 29, and 140 for herbaceous plants, shrubs, trees, fruit flies, moths, earthworms, and birds, respectively. Calculations were done using the vegan library of the R software (Oksanen et al. 2008).

At both scales, we computed a standardized index of species richness, modified from Dunn (2004), that reduced most of the species richness variation into a single metric. We transformed each value of estimated regional richness (ACE index) or local rarefied richness as a percentage of the highest value observed at the relevant scale for the corresponding taxonomic group. The resulting data set was composed of normalized species richness that ranged from 0 to 100 for each group of organisms. The standardized index of species richness was calculated for each farm and each area as the mean of the transformed richness of the seven focal groups; it also ranged from 0 (theoretical farm or area where species richness was null for all the groups) to 100 (theoretical farm or area where species richness in all groups were the highest observed values). Pairwise correlations in species richness among the focal groups of organisms were assessed with Spearman correlation index.

\section{Landscape effects on species richness}


We used remote sensing to describe landscape composition and structure within each farm. Our set of metrics included total area of land use and relative percentages, edge density, mean patch density, patch diversity (patch richness, Shannon diversity, Shannon evenness, and dominance), and fractal structures (perimeter/area, mean shape). We used available Landsat images for 1990, 1994, 1998, 2002, and 2007. These metrics were further used to calculate a single index of land-use intensity (LI) (Oszwald et al. 2011) that integrates the current pattern and the dynamics of the landscapes (Supporting Information).

We also used these metrics to assess the specific effect of five potential landscape drivers (Table on species richness: forest loss based on relative cover of mature forests (percentage of farm area); agricultural intensification based on the relative cover of agricultural land (percentage of farm area covered by pastures and crops); landscape fragmentation based on total edge density, which appeared to be significantly correlated with other metrics describing landscape structure and diversity (Oszwald et al. 2011); forest quality based on the proportion of forest in a given farm that was undisturbed during the past 17 years (hereafter undisturbed forest); and landscape dynamics, calculated using Euclidean distance with the daisy function in the R cluster library as the mean between-year land-use turnover (i.e., change in land-use composition) from 1990 to 2007 (Maechler et al. 2012). See Oszwald et al. (2011) and Supporting Information for further details.

Co-inertia analysis was conducted to assess the relationships between the rarefied richness of the 7 focal groups of organisms and the landscape drivers measured in the 54 farms. Co-inertia analysis consists of a simultaneous ordination of 2 tables (for instance an environmental and a floristic/faunistic table) that share the same row codes and provides axes that maximize the covariation between them (Dolédec \& Chessel 1994; Dray et al. 2003). In the present case, we used the ADE-4 package for R (Dray \& Dufour 2007) to independently performed principal component analysis (PCA) on each table and used their results to run the 
co-inertia analysis. This allowed a simultaneous ordination of the 7 focal groups according to the 5 landscape drivers in the 54 farms and provided a measure of the global similarity among the data sets (matrix correlation coefficient Rv) that we tested using a Monte Carlo permutation test (999 randomizations).

Graphical exploration of the data suggested the relationship among local species richness, land-use intensity, and individual landscape metrics was often nonlinear and was characterized in some cases by an abrupt change along predictors. Thus, we adjusted species richness to landscape metrics with 3 kinds of models and selected the one with the best AIC. The 3 models included simple linear effect of a predictor, segmented linear model effect, or nonlinear logistic model effect. Segmented analyses automatically estimating the break point in the predictor were performed with the segmented and MASS package of R. Linear and logistic regressions were done using the $\mathrm{lm}$ and SSlogis functions of the stats package. Only the best model for each predictor is shown on figures, and nonsignificant models are not shown.

\section{Results}

In total, we sampled or recorded $>3,800$ species, including 100 species of fruit-flies, 136 species of moths, 338 species of birds, 21 species of earthworms, and 1746, 1049, and 414 species of herbaceous plants, shrubs, and trees, respectively. At the regional scale (Figure $2 \&$ Supporting Information), the general pattern was a transient stability of species pools at the beginning of the landscape gradient (i.e., areas of less intensive agriculture). In moderately degraded areas there was sometimes a slight increase in the number of species (e.g., fruit flies and earthworms) (Figures $2 \mathrm{~d}$ and 2f), followed by a sharp decrease beyond a threshold leading to poorly diversified assemblages in landscapes with the highest land-use intensity. The exact position of the threshold on the gradient was different among the target groups, occurring, for example, at low levels of land-use intensity for herbaceous plants and moths (Figures 2a and 2e) and at the most degraded extreme of the gradient for trees (Figure 2c). The synthetic index of regional 
richness efficiently summarized these patterns and highlighted a clear threshold in the loss of regional richness mid-way along the land-use intensity gradient (Figure $2 \mathrm{~h}$ ).

With the exclusion of birds, we found a general decrease in local richness along the landscape gradient for all our target groups (Figure 3). The rarefied richness of herbaceous plants and earthworms decreased rather monotonically (Figures 3a and 3c). Shrubs, trees, fruit flies, and moths presented a transient stability in their richness and a marked drop in richness at moderate land-use intensity (Figures 3b, 3c, 3d and 3e). As for regional diversity, local richness appeared rather constant in the first stages of forest conversion before a clear threshold was reached, mid-way along the gradient, beyond which diversity declined sharply (Figure 3h).

Co-inertia analysis highlighted a significant costructure between species richness and landscape metrics $(R v$ coefficient $=0.44$; Monte Carlo simulated $p=0.001)$. The first co-inertia axis explained $99.6 \%$ of the covariation among data sets. It separated farms with high forest cover and quality (mostly Brazilian sites) from farms with a high percentage of agricultural land cover and to a lesser extent rapid land-use turnover and high edge density (negative scores, mostly Colombian sites) (Figure 4a and SI4). Rarefied species richness of all groups of organisms had positive scores along this axis (Figure 4b), meaning biodiversity was globally and positively linked with the availability and quality of forests in the landscape and negatively linked with agriculture intensification.

Accordingly, the correlation between local species richness and the percentage of forest ecosystems showed richness stability in moderately deforested farms $(40-50 \%$ of forest dominance) and a clear threshold between $30 \%$ and $40 \%$ of forest coverage below which biodiversity tended to decline rapidly (Figure 5a). Differences between farms with comparable forest cover were further explained by differences in the quality of the forest patches, here defined as the percentage of undisturbed forests (Figure $5 \mathrm{~b}$ ). We also observed an almost linear 11 This article is protected by copyright. All rights reserved. 
decrease of local richness as the proportion of agricultural lands increased in the landscape (Figure 5c). No significant relationship occurred between local richness and land-use turnover or total edge density (Supporting Information).

Although positive and significant correlations of local species richness occurred with all possible pairwise comparisons between groups (Supporting Information), the average correlation was low (mean $r=0.54$ ). Birds and moths were poorly correlated with other groups (0.33 and 0.41 , respectively), whereas other groups of animals had higher correlations $(0.57$ and 0.58 for fruit flies and earthworms, respectively). Plant richness was more closely correlated to the other groups ( 0.61 for the herbaceous layer and 0.63 for shrubs and trees). Average between-group correlations of ACE-estimated regional richness was higher than that observed at the local scale (mean $r=0.71$ ), but pairwise comparisons were significant in only 7 cases out of 21 (Supporting Information). For the comparison between shrub and herbaceous plant layers, $p$ was $<0.01$, whereas other significant pairwise comparisons had $p$ values from 0.01 to 0.05 .

\section{Discussion}

We identified a dramatic impact of land-use intensity on Amazonian biodiversity. The clear threshold we found in the response of cross-taxonomic species richness to land-use intensity represents significant empirical support for the existence of tipping points in the response of biodiversity to deforestation and land-use intensity. Although Brazilian and Colombian sites may not have originally equivalent species diversity, this threshold is supported for some focal taxa within species pools of equivalent size in both regions, or even larger species pools in Colombia (Supporting Information). This finding suggests loss of species richness could have been underestimated in the higher range of our gradient. Such a nonlinear decrease in species richness following deforestation is predicted by ecological theory (Andren 1994; Wilson 2002; Lindenmayer et al. 2008), but little empirical evidence has been collected so far to test for such a 
pattern, especially at the landscape scale. To date, the validity of the threshold hypothesis has been questioned by authors who believe minor changes in native vegetation cover will not result in abrupt biodiversity changes due to contrasting responses of individual species (Lindenmayer et al. 2008; Pardini et al. 2010). However, in spite of the variety of the groups considered, we found that overall local biodiversity dropped steeply when forest cover fell below 30-40\%. This threshold value is in the higher range of those predicted by Andren (1994), who hypothesized the existence of a universal threshold value around $10-30 \%$ of native vegetation cover. It is also consistent with the results of Rigueira et al. (2013), who found a 6fold decrease in Myrtaceae species richness when forest cover drops below 30-40 \% in the Brazilian Atlantic Forest. We also found that forest patch quality was an important factor in explaining biodiversity dynamics in deforested landscapes, which is consistent with the results of Barlow et al (2016), who highlighted that forest disturbance in individual forests and at the landscape level can explain a significant proportion of conservation value loss in Amazonian landscapes.

Landscape structure (total edge density) and temporal dynamics did not explain biodiversity patterns, which suggests habitat amount may have greater effects than habitat fragmentation (Andren 1994). This is an unexpected result because the link between landscape composition and fragmentation is well established especially in the context of deforestation fronts, where intensification of land use results in an increase in anthropic ecosystems and a reduction of the average size of landscape units (and consequently an increase in total edge density). Our finding that temporal dynamics did not explain biodiversity patterns also contrasts with the results of other studies that show patch temporal turnover does affect biodiversity (Fischer 2001; Ernoult et al. 2006). One explanation for this is that we considered several taxa with potentially different ecological responses to landscape dynamics, which could have blurred the global response of biodiversity to landscape structure and land use turnover. 
Besides the clear threshold for loss of overall species richness as land use intensifies, significant variations in the response patterns among our focal groups were apparent. For instance, the species richness of herbaceous plants, trees, and earthworms dropped sooner at the local than at the regional scale, suggesting that forest patches allowed these groups to maintain transient pools of species regionally or that the extinction of forest species was temporarily compensated by the invasion of extraregional species adapted to agricultural land uses. By contrast, shrubs, fruit flies, and birds presented simultaneous variations of their regional and local richness with land-use intensity, indicating that local species extirpations rapidly trigger extirpations at the regional scale. Moths showed a rather idiosyncratic pattern; regional richness decreased more rapidly than local richness, which may be explained by a transient decrease in community turnover at moderate levels of land-use intensity, allowing for a higher proportion of the regional species pool to occur in local assemblages.

Despite positive correlations among species richness of our different target groups, our results highlighted that these correlations were mostly nonsignificant at the regional scale and that only a small fraction of the variance in local species richness of one taxonomic group enabled prediction of species richness of another group. These observations follow the conclusions of previous studies conducted in other tropical environments (Lawton et al. 1998; Schulze et al. 2004). Discrepancies in the response of different taxa to deforestation can be caused by differences in their sensitivity to landscape transformation because they experience landscape changes at different spatial and temporal scales, are affected differently by changes in landscape configuration, use different habitats and resources within these landscapes, and present different dispersal capabilities to offset the effects of habitat fragmentation (Montoya et al. 2008; Gardner et al. 2009; Villard \& Metzger 2014). Therefore, species extinctions tend to occur at different levels of landscape perturbation, and the general response of species richness may differ significantly among the target groups. Altogether, these results emphasize the 
importance of considering a large range of organisms, rather than focusing on a few indicator taxa, when addressing the question of biodiversity response to forest modification and destruction (Lawton et al. 1998; Barlow et al. 2007a). The use of a synthetic index of species richness represents an efficient tool to summarize both the constancy and variability of the patterns among groups in a single and easily manageable metric.

A comparison of the total number of species observed in our samples with the estimated sizes of regional species pools for the few taxonomic groups for which this information is available suggests that an important proportion of the species potentially occurring in the surveyed regions was lacking in our study (Supporting Information). In the less affected landscapes, however, observed and estimated numbers of species for trees, fruit flies, moths, and birds were higher or in the range of those numbers found locally by Barlow et al. (2007a) in primary Amazonian forest based on a comparable sampling intensity. This suggests that although less intense agricultural landscapes are likely to sustain high levels of species richness, a number of forest species are lacking in those areas probably as a consequence of local extirpations occurring very early during the onset of the deforestation process. In agricultural landscapes, our results, however, underline the importance of old secondary vegetation, managed forests, and tree plantations in the maintenance of local species richness for different groups of plants and animals (Lawton et al. 1998; Barlow et al. 2007a).

Finally, our findings improve substantially understanding of the importance of landscape structure and dynamics for the maintenance of biodiversity in human-affected areas. The sharp threshold observed for the biodiversity response to land-use intensity is mainly explained by forest availability and quality. Species richness was not maintained when forest cover fell below $40 \%$ and when forest patches contained $<50 \%$ of undisturbed forest. An interesting correlate is that biodiversity loss may be mitigated either by sustaining forest quality (maintaining a high proportion of primary forest in the remaining patches) in highly 
deforested landscapes or by maintaining large forest surfaces in regions where forest has been extensively degraded. Landscape fragmentation and dynamics seemed of lesser importance for the taxa we studied. Our findings therefore suggest that anthropogenic landscapes with highquality forests covering $>40 \%$ of the surface area (Figure $5 a-b$ ) may have a significant potential to offset biodiversity loss in Amazonia.

Although this result provides valuable clues for identifying landscape management options toward meeting the challenges of biodiversity conservation and economic development in rural areas, it could be mistakenly used to justify the development of agriculture in still intact forest areas. The applicability of our findings must be considered with caution and should not be considered outside the context of already degraded landscapes because the maintenance of species richness alone may not represent a sufficient indicator of conservation success (Barlow et al. 2007a). For instance, the use of biodiversity metrics to measure the dissimilarity in community composition between intact forests and anthropogenic landscapes or to examine species life-trait shifts along deforestation gradients, although not possible in our study, should be considered in future cross-taxonomic studies. If we could have conducted such investigations, we would have been able to determine the relative importance of intact forest to species along the gradient of agricultural development or to determine species that are particularly sensitive to forest degradation. Additionally, the presence of a threshold at intermediate levels of deforestation does not exclude the possibility of an early drop in biodiversity at the onset of the deforestation process; we did not considered this.

However, identifying relevant landscape characteristics for biodiversity conservation in agricultural lands paves the way to a definition of management policies for the reconstruction of sustainable landscapes, which will help reduce biological erosion by complementing the existing networks of protected forest areas. For instance, both Colombia and Brazil have the political will to preserve their forest resources and reforest already degraded areas (e.g., $20 x 20$ initiative in 
Colombia and the revised Forest Code in Brazil [Casa Civil 2012]). However, existing policies are often not applicable (Vedovato et al. 2016; Landau et al. 2012) and do not consider the quality of forest patches (e.g., up to $50 \%$ of non-native tree species are allowed in reforested areas in Brazil). Our results suggest that current legislation imposes fragile conditions on the conservation of biodiversity in rural landscapes and that the quality of forest remnants should be better considered when dealing with biodiversity monitoring.

\section{Acknowledgments}

This work is dedicated to the late J. C. Ribeiro da Silva and M. do Espirito Santo Da Silva whose farm was one of the study sites of this work. Their murder on 24 May 2011 in Maçaranduba is doubtlessly tied to their strong engagement in the preservation of biodiversity in Brazilian Amazonia and the development of sustainable agriculture in the region. We thank all the colleagues from the Federal University of Pará (Maraba campus, Brazil), Universidad de la Amazonia (Florencia, Colombia), Museu Paraense Emilio Goeldi (Belém, Brazil), and the Institut Recherche pour le Développement (Paris, France) for their critical logistical support of this study. We are also grateful to the Brazilian, Colombian, and French students who enthusiastically participated in field sampling and helped process the enormous number of samples and data sets, the Brazilian and Colombian technical and field staff, especially D. da Costa Carvalho and M. Cordeiro, and the Brazilian and Colombian farmers for allowing us to carry out our study. This study was supported through grants from the French Agence Nationale de la Recherche and the Brazilian National Council of Research to the project AMAZ.

\section{Supporting information}

Details on the selection of study sites and calculation of the land use index (Appendix S1), questionnaire used for farmers interviews in the socioeconomic survey of agricultural systems (in Portuguese) (Appendix S2), and species' pool estimated sizes for some taxa, rarefaction curves, additional results of the co-inertia analysis, nonsignificant correlations between species 
richness and landscape metrics, and pairwise correlations (Spearman's rank correlation) of local and regional species richness among all groups of organisms (Appendix S3) are available online.

\section{Literature Cited}

Andren H. 1994. Effects of habitat fragmentation on birds and mammals in landscapes with different proportions of suitable habitat - a review. Oikos 71: 355-366.

Barlow J, et al. 2007a. Quantifying the biodiversity value of tropical primary, secondary, and plantation forests. PNAS 104: 18555-18560.

Barlow J, Mestre LAM, Gardner TA, Peres CA. 2007b. The value of primary, secondary and plantation forests for Amazonian birds. Biological Conservation 136: 212-231.

Barlow J, et al. 2016. Anthropogenic disturbance in tropical forests can double biodiversity loss from deforestation. Nature 535: 144-147.

Butler R. 2017. Calculating deforestation figures for the Amazon. https://rainforests.mongabay.com/amazon/deforestation_calculations.html

Cardoso Da Silva JM, Rylands AB, Da Fonseca GAB. 2005. The fate of the Amazonian areas of endemism. Conservation Biology 19: 689-694.

Casa Civil, Presidência da República. 2012. Lei № 12.651, de 25 de maio de 2012. http://www.planalto.gov.br/ccivil_03/_ato2011-2014/2012/lei/L12651compilado.htm

Chao A, Jost L. 2012. Coverage-based rarefaction and extrapolation: standardizing samples by completeness rather than size. Ecology 93: 2533-2547.

Chao A, Lee S-M. 1992. Estimating the number of classes via sample coverage. Journal of the American Statistical Association 87: 210-217.

This article is protected by copyright. All rights reserved. 
Chazdon RL, et al. 2009. Beyond reserves: A research agenda for conserving biodiversity in human - modified tropical landscapes. Biotropica 41(2): 142-153.

Collen B, Loh J, Whitmee S, McRae L, Amin R, Baillie JEM. 2009. Monitoring change in vertebrate abundance: the Living Planet Index. Conservation Biology 23: 317-327.

Diaz S, Lavorel S, de Bello F, Quétier F, Grigulis K, Robson TM. 2007. Incorporating plant functional diversity effects in ecosystem service assessments. Proceedings of the National Academy of Sciences 104: 20684-20689.

Decaëns T. 2010. Macroecological patterns in soil communities. Global Ecology And Biogeography 19: 287-302.

Dolédec S, Chessel D. 1994. Co-inertia analysis: an alternative method for studying speciesenvironment relationships. Freshwater Biology 31: 277-294.

Dray S, Chessel D, Thioulouse J. 2003. Co-inertia analysis and the linking of the ecological data tables. Ecology 84: 3078-3089.

Dray S, Dufour AB. 2007. The ade4 package: implementing the duality diagram for ecologists. Journal of Statistical Software 22: 1-20.

Dunn RR. 2004. Managing the tropical landscape: a comparison of the effects of logging and forest conversion to agriculture on ants, birds, and lepidoptera. Forest Ecology and Management 191: 215-224.

Ernoult A, Tremauville Y, Cellier D, Margerie P, Langlois E, Alard D. 2006. Potential landscape drivers of biodiversity components in a flood plain: past or present patterns? Biological Conservation 127: 1. 
Estavillo C, Pardini R, da Rocha PLB. 2013. Forest loss and the biodiversity threshold: an evaluation considering species habitat requirements and the use of matrix habitats. PloS One 8: e82369.

Fazey I, Fischer J, Lindenmayer DB. 2005. What do conservation biologists publish? Biological Conservation 124: 63-73.

Fischer M. 2001. Landscape dynamics can accelerate metapopulation extinction. Trends in Ecology \& Evolution 16: 225-226.

Gardner TA, Barlow J, Chazdon RL, Ewers RM, Harvey CA, Peres CA, Sodhi NS. 2009. Prospects for tropical forest biodiversity in a human-modified world. Ecology Letters 12: 561-582.

Gottschalk MS, De Toni DC, Valente VLS, Hofmann PRP. 2007. Changes in Brazilian Drosophilidae (Diptera) assemblages across an urbanisation gradient. Neotropical Entomology 36: 848-862.

Haddad NM, et al. 2015. Habitat fragmentation and its lasting impact on Earth's ecosystems. Science Advances 1(2): e1500052.

Hawes J, da Silva Motta C, Overal WL, Barlow J, Gardner TA, Peres CA. 2009. Diversity and composition of Amazonian moths in primary, secondary and plantation forests. Journal of Tropical Ecology 25: 281-300.

Lamarre G, Mendoza I, Rougerie R, Decaëns T, Hérault B, Bénéluz F. 2015. Stay out (almost) all night: contrasting responses in flight activity among tropical moth assemblages. Neotropical Entomology 44: 109-115.

Landau EC, da Cruz RK, Hirsch A, Pimenta FM, Pereira Guimarães D. 2012. Variação geográfica do tamanho dos Módulos Fiscais no Brasil. Documentos No. 146, Embrapa Milho e Sorgo, Sete Lagoas. 
Lavelle P, et al. 2016a. Unsustainable landscapes of deforested Amazonia: An analysis of the relationships among landscapes and the social, economic and environmental profiles of farms at different ages following deforestation. Global Environmental Change 40: 137155.

Lavelle P, Spain A, Blouin M, Brown G, Decaëns T, Grimaldi M, Jiménez JJ, McKey D, Mathieu J, Velasquez E, Zangerlé A. 2016b. Ecosystem engineers in a self-organized soil: A review of concepts and future research questions. Soil Science 181(3/4): 91-109.

Lawton JH, et al. 1998. Biodiversity indicators, indicator taxa and effects of habitat modification in tropical forest nature. Biodiv. Invent. Nat 391: 72-76.

Lindenmayer D, et al. 2008. A checklist for ecological management of landscapes for conservation. Ecology Letters 11: 78-91.

Maechler M, Rousseeuw P, Struyf A, Hubert M, Hornik K. 2012. Cluster: Cluster Analysis Basics and Extensions. R package version 1.14.3.

Martins MB, Pena JAN, Bittencourt RN. 2008. Traps for tropical drosophilids survey. Drosophila Information Service 91: 91-91.

Melo GL, Sponchiado J, Cáceres NC, Fahrig L. 2017. Testing the habitat amount hypothesis for South American small mammals. Biological Conservation 209: 304-314.

Montoya D, Zavala MA, Rodríguez MA, Purves DW. 2008. Animal versus wind dispersal and the robustness of tree species to deforestation. Science 320: 1502-1504.

Myers N. 1984. The Primary Source: Tropical Forests and Our Future. W.W. Norton, New York.

Newbold T, et al. 2014. A global model of the response of tropical and sub-tropical forest biodiversity to anthropogenic pressures. Proc. R. Soc. B Biol. Sci. 281: 20141371. 
Newbold T, et al. 2015. Global effects of land use on local terrestrial biodiversity. Nature 520: 45-50.

Oksanen J, Kindt R, Legendre P, O'Hara B, Simpson GL, Stevens MHH, Wagner H. 2008. Vegan: Community Ecology Package. R package version 1.13-1. http://vegan.r-forge.rproject.org/.

Oszwald J, Gond V, Dolédec S, Lavelle P. 2011. Identification d'indicateurs de changement d'occupation du sol pour le suivi des mosaïques paysagères. Bois et Forêts des Tropiques 307: 7-21.

Pardini R, Bueno AD, Gardner TA, Prado PI, Metzger JP. 2010. Beyond the Fragmentation Threshold Hypothesis: Regime Shifts in Biodiversity Across Fragmented Landscapes. PLoS One 5.

Peres CA, Gardner TA, Barlow J, Zuanon J, Michalski F, Lees AC, Vieira ICG, Moreira FMS, Feeley KJ. 2010. Biodiversity conservation in human-modified Amazonian forest landscapes. Biological Conservation 143: 2314-2327.

R Development Core Team. 2011. R: A language and environment for statistical computing. R Foundation for Statistical Computing, Vienna, Austria. http://www.R-project.org. Rigueira DMG, da Rocha PLB, Mariano-Neto E. 2013. Forest cover, extinction thresholds and time lags in woody plants (Myrtaceae) in the Brazilian Atlantic Forest: resources for conservation. Biodiversity Conservation 22: 3141-3163.

Rodrigues ASL, et al. 2004. Effectiveness of the global protected area network in representing species diversity. Nature 428: 640-643.

Schulze CH, et al. 2004. Biodiversity indicator groups of tropical land-use systems: Comparing plants, birds, and insects. Ecological Applications 14: 1321-1333. 
Vedavato LB, Fonseca MG, AraiE, Oighenstein Anderson L, Aragão LEOC. 2016. The extent of 2014 forest fragmentation in the Brazilian Amazon. Regional Environmental Change 16: $2485-2490$.

Villard M-A, Metzger J-P. 2014. Beyond the fragmentation debate: a conceptual model to predict when habitat configuration really matters. Journal of Applied Ecology 51, 309-318.

Wilson EO. 2002. The future of life. Vintage Books, New York.

Table 1. Main characteristics of the Amazonian landscapes in the 6 agricultural areas examined.

\begin{tabular}{|c|c|c|c|c|c|c|c|c|c|c|c|c|c|}
\hline \multirow{3}{*}{$\begin{array}{l}\text { Landscape } \\
\text { (code) }\end{array}$} & \multirow{3}{*}{$\begin{array}{l}\text { Colonizati } \\
\text { on (years)a }\end{array}$} & \multicolumn{8}{|c|}{ Land cover $2007(\%)^{\mathrm{b}}$} & \multicolumn{3}{|c|}{ Metricc } & \multirow[b]{3}{*}{ LI } \\
\hline & & & & $\mathrm{U}$ & & & & $\mathrm{W}$ & B & Fqual & $\mathrm{ED}(\mathrm{m}$ & LUTO & \\
\hline & & FO & $\mathrm{BF}$ & W & PA & LP & FA & $\mathrm{A}$ & S & $(\%)$ & ha $^{-1}$ ) & $(\%)$ & \\
\hline & & 77 & 19. & & & & & & 0. & & & & 0.2 \\
\hline Pacajá (A) & 10 & 1 & 4 & 1.6 & 0.2 & 0.1 & 1.5 & 0.0 & 1 & 0.88 & 476.2 & 19.8 & 1 \\
\hline Palmares & & 81 & & & & & & & 0. & & & & 0.3 \\
\hline (B) & 20 & 7 & 9.4 & 1.4 & 0.1 & 0.0 & 7.0 & 0.0 & 3 & 0.78 & 689.0 & 15.0 & 8 \\
\hline Maçarandu & & 22 & 10. & 15. & 10. & 12. & 27. & & 0. & & & & 0.5 \\
\hline ba (C) & 40 & 7 & 9 & 6 & 0 & 8 & 9 & 0.0 & 0 & 0.49 & 622.6 & 31.9 & 1 \\
\hline
\end{tabular}

This article is protected by copyright. All rights reserved. 
Aguadulce

(D)

$>80$

$\begin{array}{lll}1.5 & 0.0 & 1\end{array}$

45.

10. 14. 20. 0 .

0.7

Balcanes

18. 11.29.

$\begin{array}{lll}4.2 & 0.0 & 7\end{array}$

$>80$

(E)

19. 18. 25. 11. 23. 0.

0.8

Canelos (F) >80 $\begin{array}{lll}2.0 & 0.0 & 1\end{array}$

\section{3}

$\begin{array}{lll}0.06 & 738.3 \quad 28.6\end{array}$

4

\section{aAge of human colonization.}

bLand-cover percent calculated from 2007 Landsat images: FO, primary forests; BF, burned forests; UW, undergrowth wetlands; PA, pastures; LP, ligneous pastures; FA, fallows; WA, water areas; BS, bare soil.

c Measures of landscape structure: Fqual, forest quality (percent of forest in a given area that was undisturbed during the past 17 years), ED, total edge density; LUTO, land-use turnover (i.e., mean between-year dissimilarity in land-use composition from 1990 to 2007); LI, land-use index (0, lowest intensity; 1 , highest intensity).

This article is protected by copyright. All rights reserved. 


\section{Figure legends}

(a)
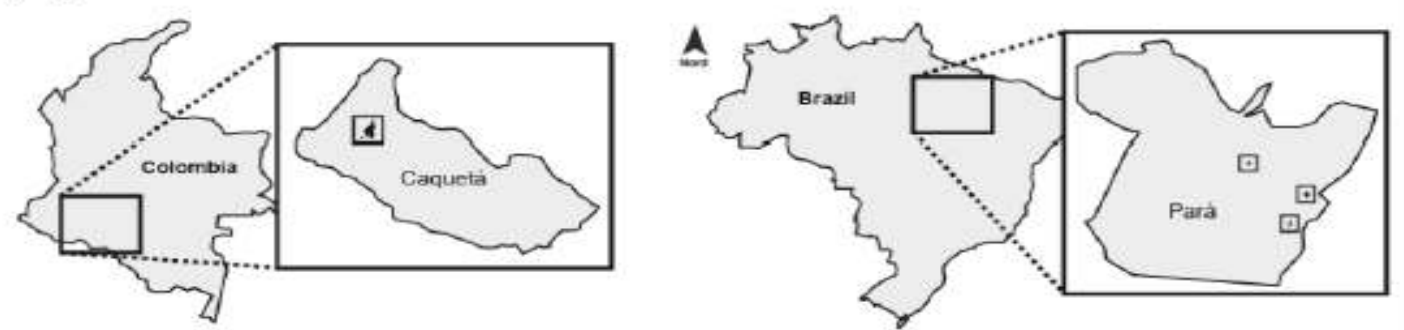

(b)
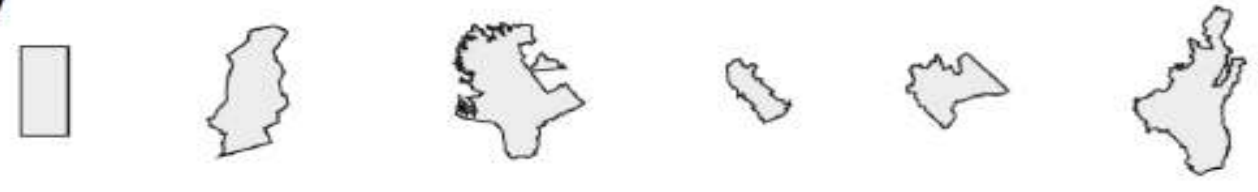

A - Pacajâ

B-Palmares

C-Maçaranduba

D-Aguadulice

E-Baicanes

F-Canelos

(c)

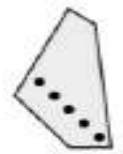

Farm 1

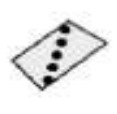

Farm 2

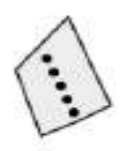

Farm 3

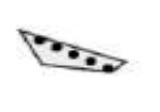

Farm 4
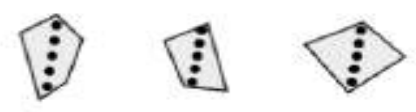

Farm 7

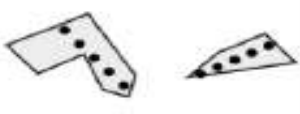

Farm $8 \quad$ Farm 9

(d)

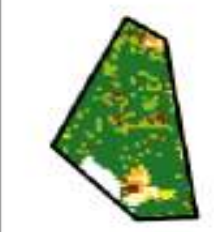

1990

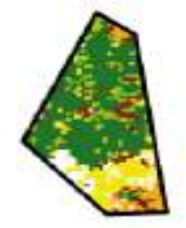

1994

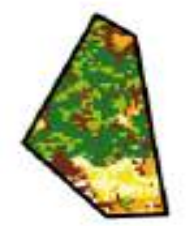

1998

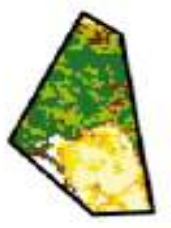

2002
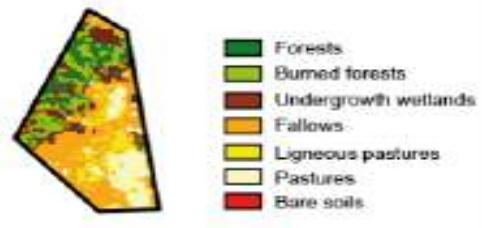

2007

Figure 1. Study sites in Amazonia and sampling design: (a) location of the 6 sites in Brazil and

Colombia selected to represent a gradient of deforestation and land-use intensity, (b) shape of each study area; (c) examples of farms selected in a given study area (here Maçaranduba) and locations of the 5 sampling points for biodiversity assessment, (d) example of how the landscape structure on 1 farm was described at 5 different dates to account for landscape dynamics.

This article is protected by copyright. All rights reserved. 


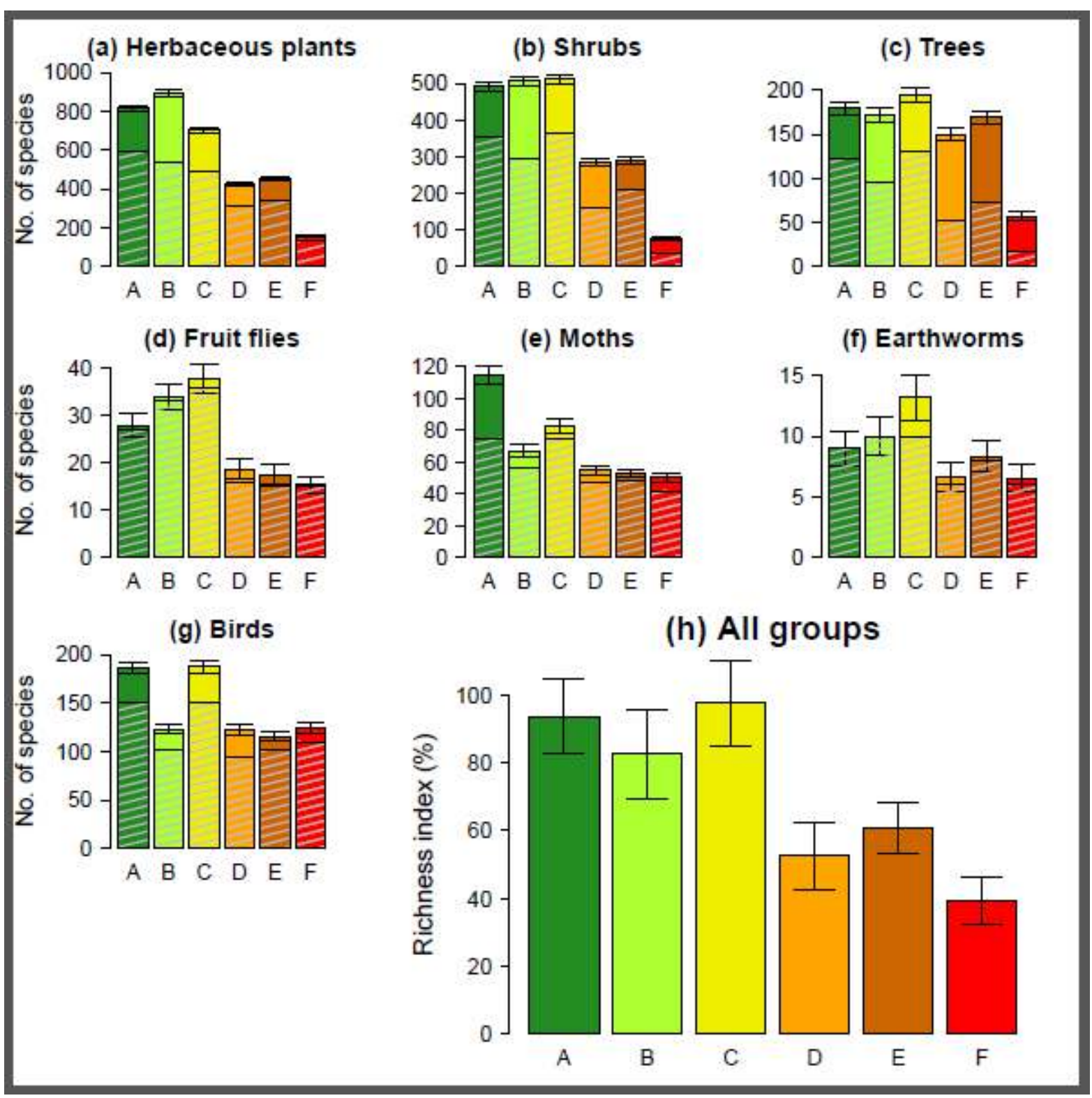

Figure 2. Variations in regional species richness with land-use intensity for : (a-g) 7 target groups and (h) overall regional biodiversity calculated for all groups with the standardized species richness index (6 landscape areas ranked by increasing level of land-use intensity (see Table 1) (A, Pacajá; B, Plamares; C, Maçaranduba; D, Aguadulce; E, Balcanes; F, Canelos; hashmarked bars ,cumulative number of species observed in each area; bars without hash marks, estimated regional richness calculated with the abundance-based coverage estimator ; vertical lines, SE).

This article is protected by copyright. All rights reserved. 


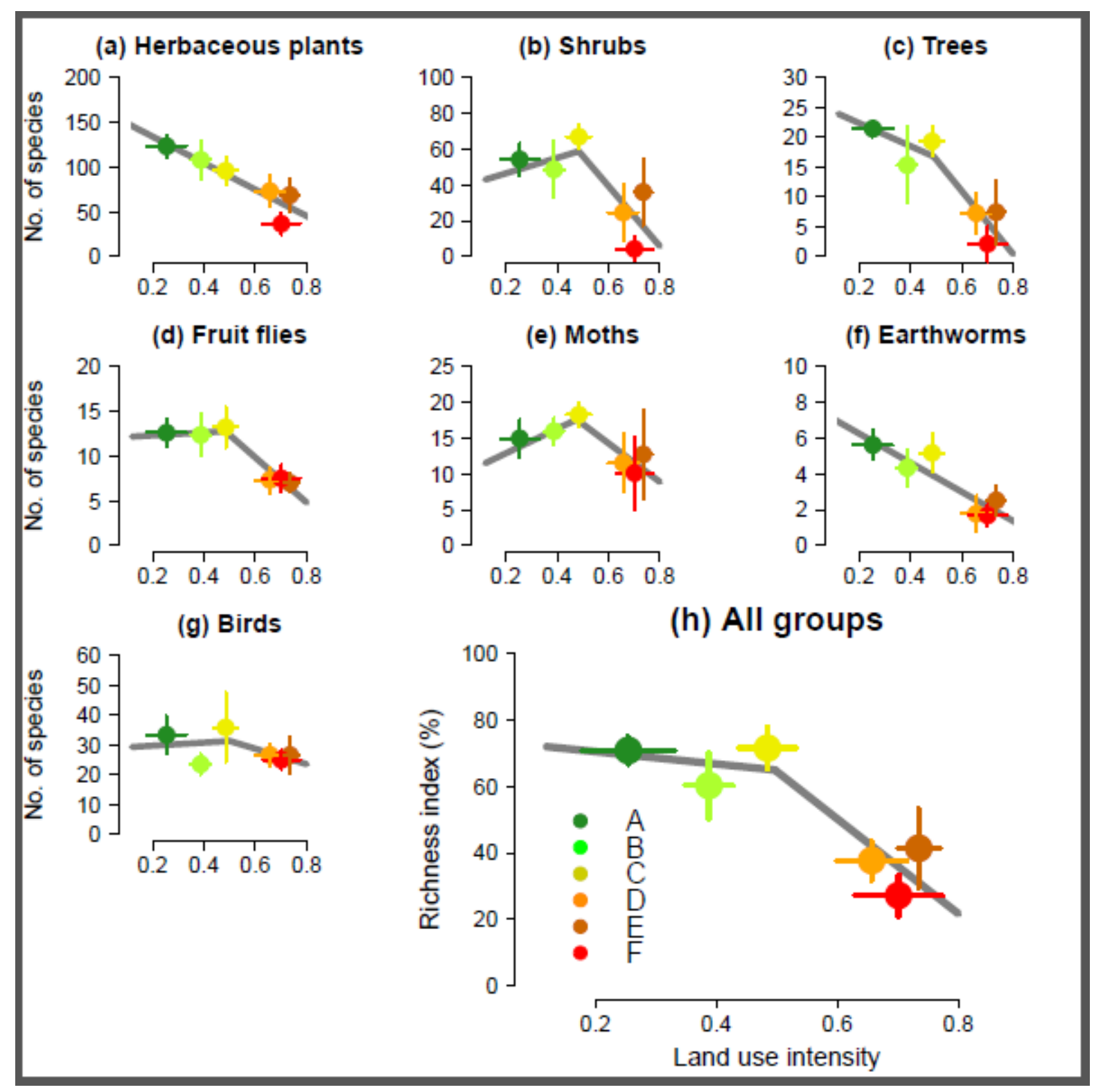

Figure 3. Relationships between local species richness and land-use intensity (0, lowest intensity; 1, highest intensity): (a-g) rarefied richness calculated for 7 target groups and (h) overall richness calculated for all groups with the standardized richness index (points, average values obtained from the different farms in each landscape).

This article is protected by copyright. All rights reserved. 


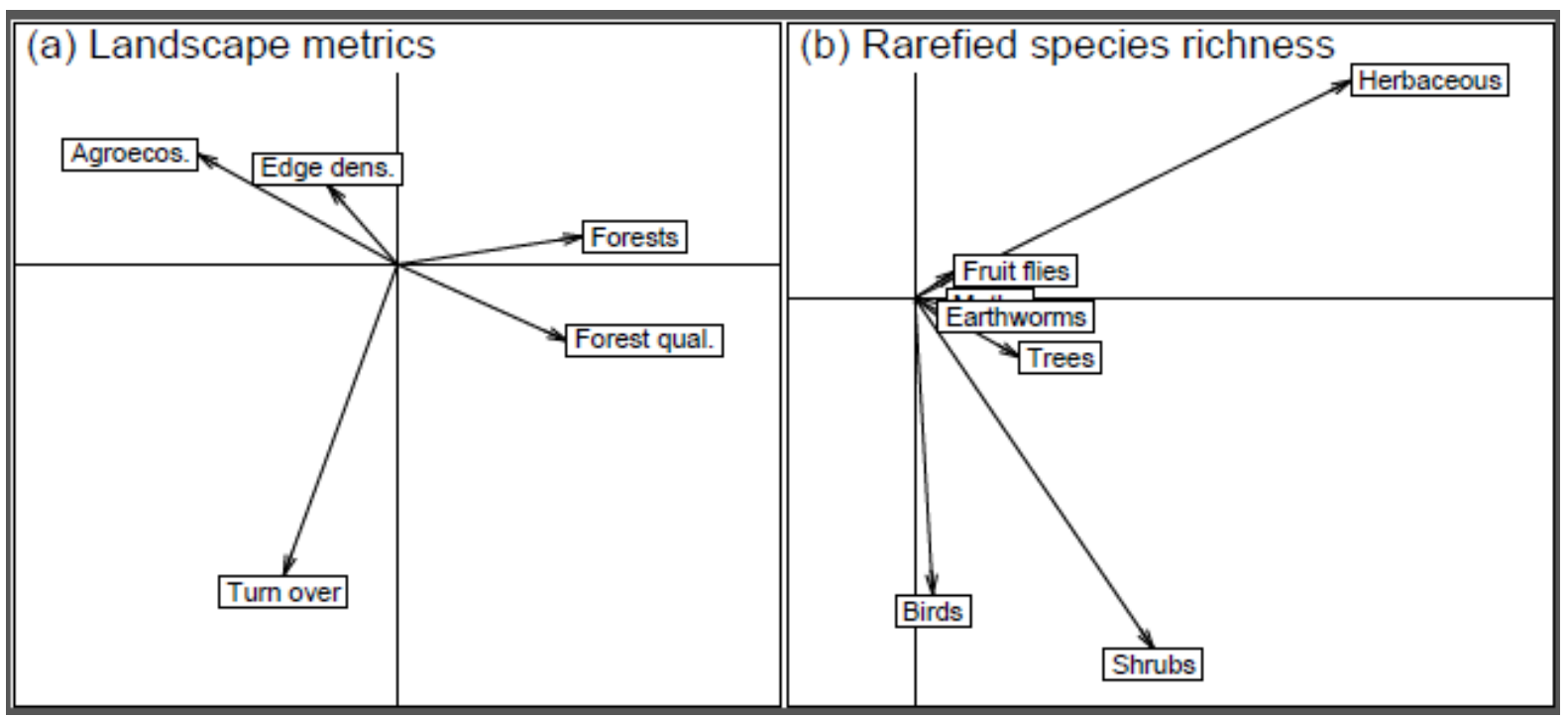

Figure 4. Contributions of (a) landscape metrics and (b) rarefied species richness to the definition of the first 2 axes of the co-inertia analysis (qual, quality).

This article is protected by copyright. All rights reserved. 


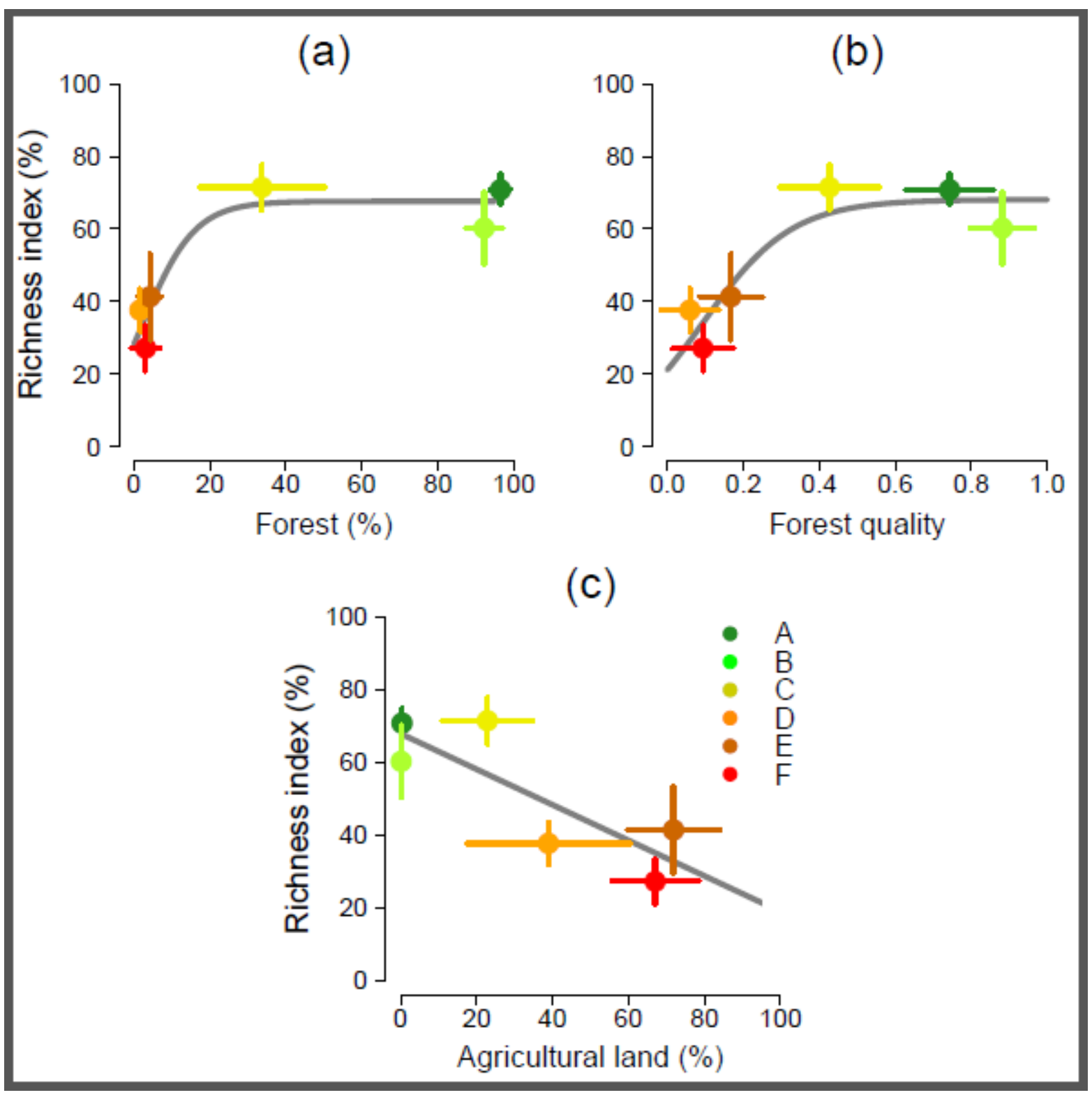

Figure 5. Relationships between the synthetic index of species richness and selected landscape metrics and (a) percent forest area, (b) forest quality, and (c) percent agricultural lands.

This article is protected by copyright. All rights reserved. 